\title{
Article \\ Effects of the COVID-19 Epidemic on Hospital Admissions for Non-Communicable Diseases in a Large Italian University-Hospital: A Descriptive Case-Series Study
}

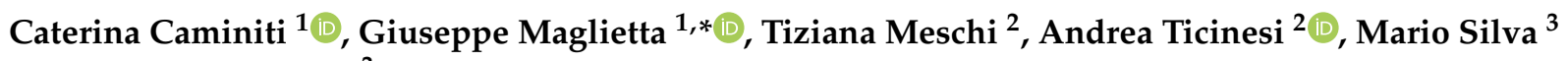 \\ and Nicola Sverzellati ${ }^{3}$ \\ 1 Research and Innovation Unit, University Hospital of Parma, 43126 Parma, Italy; ccaminiti@ao.pr.it \\ 2 Geriatric-Rehabilitation Department, University Hospital of Parma, 43126 Parma, Italy; \\ tiziana.meschi@unipr.it (T.M.); aticinesi@ao.pr.it (A.T.) \\ 3 Radiological Sciences Unit, University Hospital of Parma, 43126 Parma, Italy; mario.silva@unipr.it (M.S.); \\ nsverzellati@ao.pr.it (N.S.) \\ * Correspondence: gmaglietta@ao.pr.it; Tel.: +39-3408-705719
}

check for updates

Citation: Caminiti, C.; Maglietta, G.; Meschi, T.; Ticinesi, A.; Silva, M.; Sverzellati, N. Effects of the COVID-19 Epidemic on Hospital Admissions for Non-Communicable Diseases in a Large Italian University-Hospital: A Descriptive Case-Series Study. J. Clin. Med. 2021, 10, 880. https://doi.org/10.3390/ jcm10040880

Academic Editor: Giuseppe La Torre

Received: 5 January 2021

Accepted: 14 February 2021

Published: 21 February 2021

Publisher's Note: MDPI stays neutral with regard to jurisdictional claims in published maps and institutional affiliations.

Copyright: (c) 2021 by the authors. Licensee MDPI, Basel, Switzerland. This article is an open access article distributed under the terms and conditions of the Creative Commons Attribution (CC BY) license (https:// creativecommons.org/licenses/by/ $4.0 /)$.

\begin{abstract}
Background: Concern is growing about the negative consequences that response measures to the COVID-19 epidemic may have on the management of other medical conditions. Methods: A retrospective descriptive case-series study conducted at a large University-hospital in northern Italy, an area severely hit by the epidemic. Results: Between 23 February and 14 May 2020, 4160 (52\%) COVID-19 and 3778 (48\%) non-COVID-19 patients were hospitalized. COVID-19 admissions peaked in the second half of March, a period characterized by an extremely high mortality rate (27.4\%). The number of admissions in 2020 was similar to 2019, but COVID-19 patients gradually occupied all available beds. Comparison between COVID-19 and non-COVID-19 admissions in 2020 revealed significant differences concerning all age classes and gender. Specifically, COVID-19 patients were older, predominantly male, and exhibited more comorbidities. Overall, admissions for non-communicable diseases (NCDs) in 2020 vs. 2019 dropped by approximately one third. Statistically significant reductions were observed for acute myocardial infarction $(-78,-33.9 \%)$, cerebrovascular disease $(-235$, $-41.5 \%)$, and cancer $(-368,-31.9 \%)$. While the first two appeared equally distributed between COVID-19 and non-COVID-19 patients, chronic NCDs were statistically significantly more frequent in the former, except cancer, which was less frequent in COVID-19 patients. Conclusions: Prevention of collateral damage to patients with other diseases should be an integral part of epidemic response plans. Prospective cohort studies are needed to understand the long-term impact.
\end{abstract}

Keywords: COVID-19; epidemiology; hospital admissions; non-communicable diseases; coronavirus infection

\section{Introduction}

The Coronavirus disease 2019 (COVID-19) outbreak, announced as a pandemic by the World Health Organization (WHO) on 11 March 2020, imposed considerable strain on the health care systems of countries around the world [1]. Hospitals and community services were overwhelmed by the rapidly increasing number of affected patients requiring urgent care, and by the need to limit disease spread and rapidly identify and isolate new cases. In response to this unprecedented crisis, most hospitals adopted extraordinary measures, including resource reallocation, ward repurposing, and work reorganization [2,3]. At the same time, many countries enforced restrictive provisions to counter the spread of infection, including lockdowns, the closing of schools and commercial activities, social distancing, and travel restrictions [4].

These interventions, guided by the absolute priority placed on epidemic response, however, caused frequent delays or interruptions to ordinary care, particularly for people 
affected by non-communicable diseases (NCDs) [5,6]. Such changes to routine care could potentially affect quality-adjusted life years, making the socio, clinical, and economic impact of NCDs even worse. There are almost 94 million persons aged 65 and over in the $\mathrm{EU}$, accounting for an $18.5 \%$ share of the population, and the majority of persons in this age group have multimorbidity, defined as multiple concurrent NCDs [7]. Stressing the importance of these issues, some authors have spoken of a "twin epidemic" which acted synergistically by increasing morbidity and mortality $[5,6]$.

Italy was the first European country to be hit by the COVID-19 epidemic. Since the first confirmed case identified on 20 February in Lombardy (the region of Milan) in northern Italy, the outbreak quickly spread nationwide, particularly in the north, severely affecting the National Health Service [8]. Hospitals had to enact timely organizational and structural changes to counter rapidly increasing admissions and long lengths of stay (LOS) of infected patients. These included the closure and repurposing of hospital wards, restriction of visitor hospital access, identification of external triage areas, dedicated patient transport and isolation pathways, and the cessation of elective surgery [9-12]. All this has been made more difficult following the progressive cut of the national budget in the last decade, which has led to a strong reduction in beds, placing Italy below the European average with 12.9 beds per 100,000 inhabitants, while Germany had 29.2 beds [13,14].

The University Hospital of Parma, located in the Emilia-Romagna region, was particularly involved in the health crisis, also because, being a referring center for intensive care, it also admitted many infected patients from neighboring areas. Here, a specific algorithm has been implemented to manage the flow of suspected cases, which included pre-triage and a specific pathway enabling timely COVID-19 screening and rapid admission of positive subjects to COVID-19-dedicated wards [15].

This work aims to describe the impact of the epidemic on hospitalizations, particularly of subjects with NCDs, in the context of the hospital model outlined above, by comparing data from the period of the COVID-19 outbreak with the equivalent period in 2019.

\section{Materials and Methods}

\subsection{Study Design, Setting and Participants}

Study data were anonymously extracted from the electronic hospital discharge forms (eHDFs), contained in the administrative databases of the Emilia Romagna Regional Health Trust [17], and included the following: age, sex, medical comorbidities, dates of admission and discharge, and discharge status (deceased, transferred to a different hospital or home, etc.).

EHDFs contain the main diagnosis and up to five secondary diagnoses (i.e., any conditions existing at admission or occurring during hospitalization which influence treatment or length of stay). Since the beginning of the epidemic, a field has been added where physicians are required to indicate whether the patient is being treated for COVID-19 infection.

\subsection{Data Collection}

This is a retrospective, descriptive case-series study conducted at a single academic medical center. The University-Hospital of Parma is a 1044-bed facility with a catchment area of $>400,000$ inhabitants, the second largest hospital in the Emilia-Romagna Region. In 2019, it recorded a total of 45,540 hospital admissions (of which one fifth concerned people living outside the Parma Province), 115,500 Emergency Department admissions, and 3,960,000 ambulatory services [16].

This study concerns consecutive cases hospitalized at our institution from 23 February to 14 May in the years 2019 and 2020. Data were used to measure a secondary objective of an observational study performed at the University-Hospital of Parma, approved by the local Ethics Committee. 


\subsection{Statistical Analysis}

Sample size was equal to the number of patients hospitalized during the study period without any a priori statistical calculation. Continuous variables are presented as median and interquartile ranges (IQRs) or mean and standard deviations. Categorical variables are expressed as absolute (number) and relative (percentage) of patients.

To compare categorical variables, we applied the chi-square test, the Mann-Whitney test for continuous variables expressed with median and IQRs, and the independent samples t-test in case of mean and standard deviation. Corrections for multiple testing were not applied since this is a descriptive study, without formal calculations for sample size or for statistical power, and all comparisons had only explorative purposes.

\section{Results}

Between 23 February and 14 May, 2020, there were 4160 (52\%) COVID-19 and 3778 (48\%) non-COVID-19 patients admitted to hospital. Figure 1 depicts the trend of the number of COVID-19 admissions and corresponding deaths per day (red line). COVID-19 admissions exhibited an increasing trend up to the second half of March, when the peak was reached, and then gradually decreased from April onwards. Concerning mortality, the death rate was extremely high $(27.4 \%)$ since the beginning of the outbreak up to the end of March, and then gradually decreased (9.6\%).

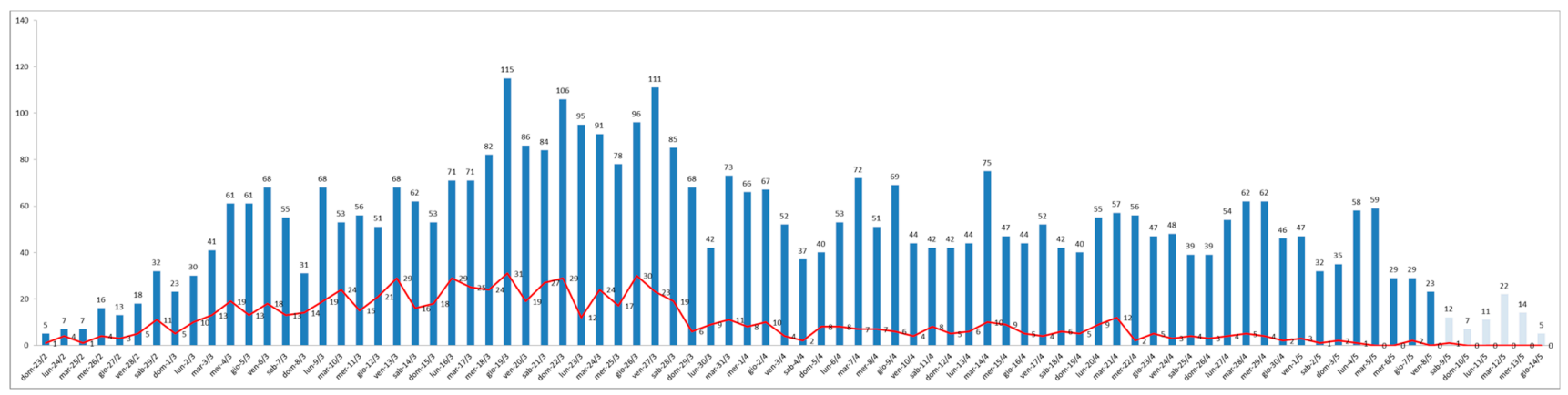

Figure 1. Trend of the number of COVID-19 admissions and corresponding deaths per day (red line).

Figure 2 shows the number of patients present in the hospital each day during the epidemic in the period under consideration. Compared with the previous year (yellow line), the number of hospitalized patients during the epidemic did not increase, and the proportion of admissions for COVID-19 and non-COVID-19 patients was similar (4160 vs. 3778), though unequally distributed through time. In fact, as the days passed, COVID-19 patients gradually occupied nearly all available beds (red bars), with a corresponding reduction of non-COVID-19 patients (blue bars).

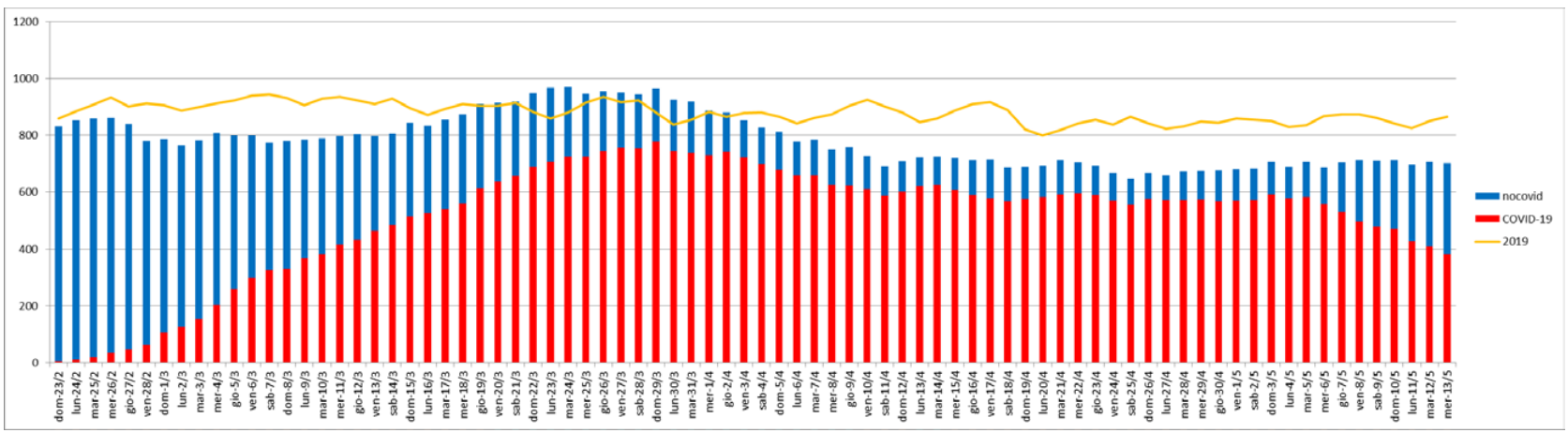

Figure 2. Number of patients present in the hospital each day during the epidemic period. 
Table 1 displays the comparison of characteristics between patients hospitalized during the epidemic and those admitted in the corresponding period of the previous year (7938 vs. $8656,-8.3 \%$ ). Statistically significant differences were seen in age distribution: in 2020, admissions of individuals $<18$ years and between 40 and 64 years decreased, while those of people over 80 years increased. Considering admissions for the NCDs that are most frequently reported in the eHDF, in 2020, statistically significant reductions were observed for acute myocardial infarction $(-78,-33.9 \%)$, cerebrovascular disease $(-235,-41.5 \%)$, and cancer $(-368,-31.9 \%)$. The comparison between COVID-19 and non-COVID-19 admissions in 2020 revealed significant differences concerning all age classes and genders. Specifically, COVID-19 patients were older, predominantly male, and exhibited more comorbidities. Regarding the frequency of NCDs, acute myocardial infarction and cerebrovascular disease appeared to be equally distributed between COVID19 and non-COVID-19 patients, whereas chronic NCDs were statistically significantly more frequent in the former. Among chronic NCDs, cancer was the only exception, as it was less frequent in COVID-19 patients (7.8\% vs. $12.1 \%$ ). Regarding admissions for urgent surgical procedures, in 2020, a reduction was observed $(-97,-37.7 \%)$, equally distributed between COVID-19 and non-COVID-19 patients.

Table 1. Baseline characteristics of hospitalized patients between 23 February and 14 May.

\begin{tabular}{|c|c|c|c|c|c|c|}
\hline & Year 2019 & Year 2020 & $p$-Value & $\begin{array}{c}\text { COVID-19 } \\
2020\end{array}$ & $\begin{array}{l}\text { Non-COVID-19 } \\
2020\end{array}$ & $p$-Value \\
\hline & $(n=8656)$ & $(n=7938)$ & & $(n=4160)$ & $(n=3778)$ & \\
\hline \multicolumn{7}{|l|}{ Age } \\
\hline Median (IQR) & $61(33-78)$ & $64(35-79)$ & $<0.001^{\mathrm{f}}$ & $73(59-82)$ & $39(11-71)$ & $<0.001^{\mathrm{I}}$ \\
\hline \multicolumn{7}{|l|}{ Class } \\
\hline 0 & $717(8.3 \%)$ & $831(10.5 \%)$ & $<0.001$ & $44(1.1 \%)$ & $787(20.8 \%)$ & $<0.001$ \\
\hline $1-17$ & $753(8.7 \%)$ & $356(4.5 \%)$ & $<0.001$ & $132(3.2 \%)$ & $224(5.9 \%)$ & $<0.001$ \\
\hline $18-39$ & $1171(13.5 \%)$ & $1075(13.5 \%)$ & 0.99 & $180(4.3 \%)$ & $895(23.7 \%)$ & $<0.001$ \\
\hline $40-64$ & $2005(23.2 \%)$ & $1701(21.4 \%)$ & 0.007 & $1040(25.0 \%)$ & $661(17.5 \%)$ & $<0.001$ \\
\hline $65-80$ & $2090(24.1 \%)$ & $1969(24.8 \%)$ & 0.67 & $1337(32.1 \%)$ & $632(16.7 \%)$ & $<0.001$ \\
\hline $80+$ & $1919(22.2 \%)$ & $1940(24.4 \%)$ & $<0.001$ & $1361(32.7 \%)$ & $579(15.3 \%)$ & $<0.001$ \\
\hline \multicolumn{7}{|l|}{ Sex } \\
\hline $\mathrm{F}$ & $4443(51.3 \%)$ & $4023(50.7 \%)$ & 0.41 & $1807(43.4 \%)$ & $2216(58.7 \%)$ & $<0.001$ \\
\hline $\mathrm{M}$ & $4212(48.7 \%)$ & $3915(49.3 \%)$ & 0.41 & $2353(56.6 \%)$ & $1562(41.3 \%)$ & $<0.001$ \\
\hline \multicolumn{7}{|l|}{ Comorbidities } \\
\hline Median (IQR) & $2(1-4)$ & $4(2-6)$ & $<0.001^{\mathrm{f}}$ & $4(3-6)$ & $2(1-4)$ & $<0.001^{\mathrm{f}}$ \\
\hline \multicolumn{7}{|l|}{ Acute NCDs } \\
\hline $\begin{array}{l}\text { Acute Myocardial } \\
\text { Infarction }\end{array}$ & $230(2.7 \%)$ & $152(1.9 \%)$ & 0.002 & $73(1.8 \%)$ & $79(2.1 \%)$ & 0.32 \\
\hline $\begin{array}{l}\text { Cerebrovascular Disease } \\
\text { (Stroke, TIA) }\end{array}$ & $566(6.5 \%)$ & $331(4.2 \%)$ & $<0.001$ & $178(4.3 \%)$ & $153(4.0 \%)$ & 0.65 \\
\hline \multicolumn{7}{|l|}{ Chronic NCDs } \\
\hline Hypertension & $1420(16.4 \%)$ & $1360(17.1 \%)$ & 0.21 & $993(23.9 \%)$ & $367(9.7 \%)$ & $<0.001$ \\
\hline Dementia & $409(4.7 \%)$ & $328(4.1 \%)$ & 0.07 & $253(6.1 \%)$ & $75(2.0 \%)$ & $<0.001$ \\
\hline $\begin{array}{c}\text { Chronic Respiratory } \\
\text { Disease (COPD, Asthma) }\end{array}$ & $418(4.8 \%)$ & $334(4.2 \%)$ & 0.6 & $246(5.9 \%)$ & $88(2.3 \%)$ & $<0.001$ \\
\hline Diabetes & $751(8.7 \%)$ & $684(8.6 \%)$ & 0.9 & $495(11.9 \%)$ & $189(5 \%)$ & $<0.001$ \\
\hline Cancer & $1152(13.3 \%)$ & $784(9.9 \%)$ & $<0.001$ & $326(7.8 \%)$ & $458(12.1 \%)$ & $<0.001$ \\
\hline \multicolumn{7}{|c|}{ Urgent surgical procedures } \\
\hline & $257(3 \%)$ & $160(2 \%)$ & $<0.001$ & $82(2 \%)$ & $78(2.1 \%)$ & 0.8 \\
\hline
\end{tabular}

${ }^{\mathrm{f}} p$-value obtained by means of Mann-Whitney Test. No correction for multiple testing was applied. TIA, Transient Ischemic Attack. 
Table 2 reports various process and outcome data. Concerning LOS, which in only $3 \%$ of cases was $<24 \mathrm{~h}$, the comparison between COVID-19 vs. non-COVID-19 patients in 2020 is particularly striking, as the value for the former was almost twice as high. This was probably due to the significantly larger proportion of elderly subjects ( $\geq 65$-year-old patients made up $64.8 \%$ of COVID-19 vs. $32 \%$ of non-COVID-19 admissions), and to the greater number of comorbidities. The number of first admissions to intensive care in the two periods under consideration overlapped; however, in 2020 these predominantly consisted of COVID-19 patients. The analysis of patients who have had at least one access to intensive care shows that the percentage of patients in 2019 was almost equal to that of COVID-19 patients in 2020 ( $8.5 \%$ and $8.2 \%$, respectively). Just as for overall LOS, LOS in intensive care was twice as long for COVID-19 patients as compared to non-COVID-19 patients in 2020, and to patients in 2019. Because of the disease severity and critical clinical conditions, the death rate among COVID-19 patients in 2020 was five times higher than the death rate in 2019 (19.2\% vs. $4.1 \%)$.

Table 2. Admissions to intensive care unit (ICU), hospital stay and in-hospital mortality.

\begin{tabular}{|c|c|c|c|c|c|c|}
\hline & Year 2019 & Year 2020 & $p$-value & $\begin{array}{l}\text { COVID-19 } \\
2020\end{array}$ & $\begin{array}{c}\text { Non-COVID-19 } \\
2020\end{array}$ & $p$-Value \\
\hline & $(n=8656)$ & $(n=7938)$ & & $(n=4160)$ & $(n=3778)$ & \\
\hline LOS—days, Mean (SD) & $8.3(11.8)$ & $7.6(10.0)$ & $<0.001 \S$ & $9.9(10.2)$ & $5.2(9.2)$ & $<0.001^{\S}$ \\
\hline First access to ICU & $333(3.8 \%)$ & $246(3.1 \%)$ & 0.08 & $160(3.8 \%)$ & $86(2.3 \%)$ & $<0.001$ \\
\hline Access to ICU at least once & $737(8.5 \%)$ & $537(6.8 \%)$ & $<0.001$ & $342(8.2 \%)$ & $195(5.2 \%)$ & $<0.001$ \\
\hline LOS—days in ICU, Mean (SD) & $5.2(8.7)$ & $7.9(11.1)$ & $<0.001 \S$ & $9.9(12.6)$ & $4.4(5.9)$ & $<0.001 \S$ \\
\hline Deaths & $351(4.1 \%)$ & $966(12.2 \%)$ & $<0.001$ & $798(19.2 \%)$ & $168(4.4 \%)$ & $<0.001$ \\
\hline
\end{tabular}

$\S p$-value obtained by means of independent samples $t$-test. No correction for multiple testing was applied. LOS, Lengths of Stay.

Comparison of the outcomes between 2020 and 2019 for individual NCDs (Supplementary Table S1) confirmed an increase in the mortality rate also for non-COVID-19 patients, in particular for acute myocardial infarction, hypertension, and dementia, where the value was at least twice as high as in 2019. Concerning ICU use, in 2020, it was less frequent for all NCDs except for cancer, especially when associated with COVID-19 (8.9\% vs. 5.5\%).

\section{Discussion}

To our knowledge, this is the first study conducted in a large Italian public institution that provides a measure of the impact of the COVID-19 outbreak on NCD hospital admissions, compared with the corresponding period in 2019. In 2020, a decrease of nearly $10 \%$ in hospital admissions was observed, with different distributions by age group and a greater frequency of patients with comorbidities. This is in line with findings in the literature highlighting age and the presence of comorbidities as risk factors for hospitalization [18]. Overall, our data confirm the observations of a large study involving 201 US hospitals, where medical admissions in April 2020, the nadir period, declined by 34.1\% [19]. Also, the decline in admissions for cerebrovascular disease and myocardial infarction is in line with experiences from all over the world. Among others, regarding coronary syndromes, a multicenter survey conducted on 54 Italian hospitals found a $48.4 \%$ reduction in admissions for AMI in one week during the COVID-19 outbreak compared with the equivalent week in $2019(p<0.001)$ [20]. Similarly, a nationwide retrospective survey on 17 Austrian centers conducted in March 2020 observed a significant decline in the number of hospital admissions due to acute coronary syndrome, reporting a relative reduction of $39.4 \%$ between the first and last calendar week [21]. As for strokes, according to a survey by the World Stroke Organization conducted across multiple countries, during the COVID-19 epidemic, the number of stroke admissions has fallen by as much as $50 \%$ [22]. 
Although the identification of the reasons leading to this phenomenon are beyond the scope of the present research, we speculate that a number of factors may have played a role. First, fear of becoming infected at the hospital may have discouraged people from seeking medical care, also following repeated invitations to reduce social contact issued by the government and the scientific community $[23,24]$. This may have been especially true in the case of milder symptoms, a hypothesis that seems to be supported by literature observations [20,25]. Interesting in this regard are the findings of Stuhr et al. [26], who found a $20 \%$ overall decline in cardiovascular admissions in January to April 2020 vs. the same period in 2019. The study highlights that this decline was mainly driven by a reduction in "discretionary admissions", while "unavoidable admissions" were unchanged. These data may also lead us to speculate on the possibility that, in regular times (2019), admissions may be influenced to some degree by psychosomatic symptoms, to which people paid less attention during the outbreak.

Another possible reason for the reduction of NCD admissions may be related to a reallocation of healthcare resources during the pandemic, which may have caused less urgent problems to be deferred, possibly leading to a high rate of underdiagnosed diseases [24]. For instance, at our hospital, the CT scanner used for lung cancer secondary prevention was assigned to COVID-19 services, leading to temporary discontinuation of lung screening programs. Finally, we cannot exclude a paradoxical beneficial effect of social containment; more relaxed lifestyles during the lockdown, as well as the decrease of air pollution, may have contributed to a true reduction of some NCDs, such as myocardial infarction [27].

Our findings relating to cancer deserve specific consideration. It is noteworthy that the drop in cancer admissions in 2020 was mostly seen in COVID-19 compared to non-COVID19 patients. We may speculate that this is suggestive of a lower incidence of COVID-19 in the oncology population, which could be explained by changes in clinical activity [28-30]. In fact, a survey conducted on the 12 medical oncology departments of the Emilia-Romagna region found that in $25 \%$ of centers the ward was temporarily closed or outpatient visits suspended, and that follow-up visits were canceled in two centers $(16.7 \%)$, delayed in seven centers $(58.3 \%)$, and performed by phone or remote assessment in seven centers (58.3\%) [30]. We are not aware of other studies reporting reduced frequencies of COVID-19 admissions for cancer patients.

The analysis of mortality rates has shown a significant increase in 2020 for nonCOVID-19 patients affected by some NCDs (acute myocardial infarction, hypertension, and dementia), a finding that deserves further investigation.

This study has some limitations. Firstly, data were taken from hospital administrative databases and were not collected prospectively for this research. However, the data quality is supposed to be similar in the two years we compared; thus, this aspect should not impact on its interpretation. Secondly, this is a single-center study; therefore, our results may have been influenced by local characteristics (disease incidence, local and regional health authority choice of restrictions, citizen behaviors and attitudes toward the epidemic, etc.). However, the similarities found with analogous research conducted in multiple countries suggests that our observations may be generalizable to other settings, and thus indicate the presence of a widespread problem. Finally, this study did not take into account reduced access to outpatient care, such as specialist consultations, tests, and screening programs, which may have had an even stronger impact on patients with NCDs.

\section{Future Implications}

The analysis of what happened during the COVID-19 epidemic is invaluable to improve response and prepare for future crises of this kind. Various actions have already been taken at the local, regional, and national levels.

One of the main lessons is the crucial role of community services and facilities and of their strong integration with specialized hospitals in ensuring continuity of care. Fortunately, the Emilia-Romagna region could benefit from well-established clinical networks 
based on a "hub and spoke" system. To ensure that citizens continued to receive appropriate care during the epidemic, with particular attention to vulnerable populations, since March 2020 the region has been issuing indications regarding specific areas (cardiology, oncology, hematology, etc.), addressed to health care professionals, defined by experts in accordance with existing guidelines and recommendations [31]. We also stress the need for educational initiatives addressed to citizens, aiming to both prevent COVID-19 infection and ensure proper management of NCDs [32]. Finally, this health emergency can be seen as an opportunity to improve and increase the integration of technology into routine patient care, such as the use of telemedicine and remote consultations. Such innovative approaches offer numerous potential advantages and are likely to be highly accepted by patients, for safety as well as logistical reasons, even after the COVID-19 crisis is over. Such potentials will be fully realized if the necessary communication infrastructure is made available to people wherever they live, and if the use of these services is ensured to all patients [33,34].

\section{Conclusions}

The consequences of the COVID-19 epidemic are not limited to patients affected by the virus. The prevention of collateral damage to patients with other diseases should be an integral part of any plan aiming to tackle such health crises. Attention to these aspects may also positively influence the outcome of vulnerable patients affected by COVID-19. Large prospective cohort studies of patients with NCDs are needed to fully understand the long-term impact of the current health crisis on these populations.

Supplementary Materials: The following are available online at https:/ /www.mdpi.com/2077-038 3/10/4/880/s1, Table S1: Admissions to ICU and in-hospital mortality for individual NCDs.

Author Contributions: C.C. conceived the study. C.C. and G.M. conceived the analysis plan and designed the study. A.T., T.M., M.S. and N.S. contributed to the study protocol and to the acquisition of data. G.M. was responsible for data analysis. C.C. and G.M. interpreted the data and drafted the initial manuscript. All authors critically revised the manuscript, approved the final work, and agree to be accountable for the accuracy and integrity of the work. All authors have read and agreed to the published version of the manuscript.

Funding: This research received no external funding.

Institutional Review Board Statement: Data were used to measure a secondary objective of an observational study performed at the University-Hospital of Parma, approved (19/03/2020) by the local Ethics Committee AVEN (Area Vasta Emilia Nord, Modena, Italy) (ID: 258/2020OSS/AOUPR).

Informed Consent Statement: Informed consent was obtained from all subjects whose data were also used for the prospective* analysis of the primary endpoint of the observational study (ID: 258/2020OSS/AOUPR). For retrospective data extracted from administrative databases, informed consent was waived by the Etihcs Committee because it was considered not feasible due to the large sample and to emergency conditions.

Data Availability Statement: The data presented in this study are available on request from the corresponding author. The data are not publicly available due to local privacy policy.

Acknowledgments: We thank Francesca Diodati for her support with literature review and analysis, as well as for writing assistance. We are grateful to Donatella Bacchieri for performing data extraction from administrative databases. Finally, we express our gratitude to the University-Hospital of Parma's Managing Director, Massimo Fabi, for strongly encouraging the authors to conduct the analyses that led to this work.

Conflicts of Interest: The authors declare no conflict of interest.

\section{References}

1. World Health Organization. Available online: https://www.who.int/emergencies/diseases/novel-coronavirus-2019 (accessed on 4 February 2021).

2. Her, M. Repurposing and reshaping of hospitals during the COVID-19 outbreak in South Korea. One Health 2020, $10,100137$. [CrossRef] [PubMed] 
3. Sen-Crowe, B.; Sutherland, M.; McKenney, M.; Elkbuli, A. A Closer Look into Global Hospital Beds Capacity and Resource Shortages During the COVID-19 Pandemic. J. Surg. Res. 2021, 260, 56-63. [CrossRef] [PubMed]

4. Mégarbane, B.; Bourasset, F.; Scherrmann, J.-M. Is Lockdown Effective in Limiting SARS-CoV-2 Epidemic Progression?-A Cross-Country Comparative Evaluation Using Epidemiokinetic Tools. J. Gen. Intern. Med. 2021, 1-7. [CrossRef]

5. Kluge, H.H.P.; Wickramasinghe, K.; Rippin, H.L.; Mendes, R.; Peters, D.H.; Kontsevaya, A.; Breda, J. Prevention and control of non-communicable diseases in the COVID-19 response. Lancet 2020, 395, 1678-1680. [CrossRef]

6. Sheldon, T.A.; Wright, J. Twin epidemics of covid-19 and non-communicable disease. BMJ 2020, 369, m2618. [CrossRef]

7. Palmer, K.; Monaco, A.; Kivipelto, M.; Onder, G.; Maggi, S.; Michel, J.-P.; Prieto, R.; Sykara, G.; Donde, S. The potential long-term impact of the COVID-19 outbreak on patients with non-communicable diseases in Europe: Consequences for healthy ageing. Aging Clin. Exp. Res. 2020, 32, 1189-1194. [CrossRef]

8. Reno, C.; Lenzi, J.; Navarra, A.; Barelli, E.; Gori, D.; Lanza, A.; Valentini, R.; Tang, B.; Fantini, M.P. Forecasting COVID-19Associated Hospitalizations under Different Levels of Social Distancing in Lombardy and Emilia-Romagna, Northern Italy: Results from an Extended SEIR Compartmental Model. J. Clin. Med. 2020, 9, 1492. [CrossRef]

9. Remuzzi, A.; Remuzzi, G. COVID-19 and Italy: What next? Lancet 2020, 395, 1225-1228. [CrossRef]

10. Sorbello, M.; El-Boghdadly, K.; Di Giacinto, I.; Cataldo, R.; Esposito, C.; Falcetta, S.; Merli, G.; Cortese, G.; Corso, R.M.; Bressan, F.; et al. The Italian coronavirus disease 2019 outbreak: Recommendations from clinical practice. Anaesthesia 2020, 75, 724-732. [CrossRef]

11. Pecoraro, F.; Clemente, F.; Luzi, D. The efficiency in the ordinary hospital bed management in Italy: An in-depth analysis of intensive care unit in the areas affected by COVID-19 before the outbreak. PLoS ONE 2020, 15, e0239249. [CrossRef] [PubMed]

12. Pasin, L.; Sella, N.; Correale, C.; Boscolo, A.; Rosi, P.; Saia, M.; Mantoan, D.; Navalesi, P. Regional COVID-19 Network for Coordination of SARS-CoV-2 outbreak in Veneto, Italy. J. Cardiothorac. Vasc. Anesthesia 2020, 34, 2341-2345. [CrossRef]

13. OECD Health at a Glance 2019. Available online: http:/ / www.oecd.org/health/health-systems / health-at-a-glance-19991312.htm (accessed on 4 February 2021).

14. Rhodes, A.; Ferdinande, P.; Flaatten, H.; Guidet, B.; Metnitz, P.G.; Moreno, R.P. The variability of critical care bed numbers in Europe. Intensiv. Care Med. 2012, 38, 1647-1653. [CrossRef]

15. Meschi, T.; Rossi, S.; Volpi, A.; Ferrari, C.; Sverzellati, N.; Brianti, E.; Fabi, M.; Nouvenne, A.; Ticinesi, A. Reorganization of a large academic hospital to face COVID-19 outbreak: The model of Parma, Emilia-Romagna region, Italy. Eur. J. Clin. Investig. 2020, 50, e13250. [CrossRef] [PubMed]

16. L'ospedale I Azienda Ospedaliero-Universitaria di Parma. Available online: https://www.ao.pr.it/chi-siamo/lospedale/ (accessed on 13 October 2020).

17. Schede di Dimissione Ospedaliera-Salute. Available online: https://salute.regione.emilia-romagna.it/siseps/sanita/sdo (accessed on 13 October 2020).

18. Pijls, B.G.; Jolani, S.; Atherley, A.; Derckx, R.T.; Dijkstra, J.I.R.; Franssen, G.H.L.; Hendriks, S.; Richters, A.; Venemans-Jellema, A.; Zalpuri, S.; et al. Demographic risk factors for COVID-19 infection, severity, ICU admission and death: A meta-analysis of 59 studies. BMJ Open 2021, 11, e044640. [CrossRef] [PubMed]

19. Birkmeyer, J.D.; Barnato, A.; Birkmeyer, N.; Bessler, R.; Skinner, J. The Impact of the COVID-19 Pandemic on Hospital Admissions in The United States. Health Aff. 2020, 39, 2010-2017. [CrossRef] [PubMed]

20. De Rosa, S.; Spaccarotella, C.; Basso, C.; Calabrò, M.P.; Curcio, A.; Filardi, P.P.; Mancone, M.; Mercuro, G.; Muscoli, S.; Nodari, S.; et al. OUP accepted manuscript. Eur. Heart J. 2020, 41, 2083-2088. [CrossRef]

21. Metzler, B.; Siostrzonek, P.; Binder, R.K.; Bauer, A.; Reinstadler, S.J. Decline of acute coronary syndrome admissions in Austria since the outbreak of COVID-19: The pandemic response causes cardiac collateral damage. Eur. Heart J. 2020, 41, 1852-1853. [CrossRef]

22. Markus, H.S.; Brainin, M. COVID-19 and stroke-A global World Stroke Organization perspective. Int. J. Stroke 2020, 15, 361-364. [CrossRef]

23. Ebinger, J.E.; Shah, P.K. Declining Admissions for Acute Cardiovascular Illness: The Covid-19 Paradox. J. Am. Coll. Cardiol. 2020, 76, 289-291. [CrossRef]

24. Schwarz, V.; Mahfoud, F.; Lauder, L.; Reith, W.; Behnke, S.; Smola, S.; Rissland, J.; Pfuhl, T.; Scheller, B.; Böhm, M.; et al. Decline of emergency admissions for cardiovascular and cerebrovascular events after the outbreak of COVID-19. Clin. Res. Cardiol. 2020, 1-7. [CrossRef]

25. Baracchini, C.; Pieroni, A.; Viaro, F.; Cianci, V.; Cattelan, A.M.; Tiberio, I.; Munari, M.; Causin, F. Acute stroke management pathway during Coronavirus-19 pandemic. Neurol. Sci. 2020, 41, 1003-1005. [CrossRef] [PubMed]

26. Stöhr, E.; Aksoy, A.; Campbell, M.; Al Zaidi, M.; Öztürk, C.; Vorloeper, J.; Lange, J.; Sugiura, A.; Wilde, N.; Becher, M.U.; et al. Hospital admissions during Covid-19 lock-down in Germany: Differences in discretionary and unavoidable cardiovascular events. PLoS ONE 2020, 15, e0242653. [CrossRef]

27. Niccoli, G.; Luescher, T.F.; Crea, F. Decreased myocardial infarction admissions during COVID times: What can we learn? Cardiovasc. Res. 2020, 116, e126-e128. [CrossRef] [PubMed]

28. Al-Shamsi, H.O.; Alhazzani, W.; Alhuraiji, A.; Coomes, E.A.; Chemaly, R.F.; Almuhanna, M.; Wolff, R.A.; Ibrahim, N.K.; Chua, M.L.; Hotte, S.J.; et al. A Practical Approach to the Management of Cancer Patients During the Novel Coronavirus Disease 2019 (COVID-19) Pandemic: An International Collaborative Group. Oncologist 2020, 25, e936-e945. [CrossRef] 
29. Curigliano, G. How to Guarantee the Best of Care to Patients with Cancer During the COVID-19 Epidemic: The Italian Experience. Oncology 2020, 25, 463-467. [CrossRef] [PubMed]

30. Brandes, A.A.; Ardizzoni, A.; Artioli, F.; Cappuzzo, F.; Cavanna, L.; Frassineti, G.L.; Frassoldati, A.; Leonardi, F.; Longo, G.; Maestri, A.; et al. Fighting cancer in coronavirus disease era: Organization of work in medical oncology departments in Emilia Romagna region of Italy. Future Oncol. 2020, 16, 1433-1439. [CrossRef]

31. Regione Emilia Romagna. COVID 19: Indicazioni Organizzative per le Reti Cliniche Integrate Ospedale-Territorio. Available online: https: / / salute.regione.emilia-romagna.it/assistenza-ospedaliera / covid-19-indicazioni-organizzative-per-le-reti-clinicheintegrate-ospedale-territorio (accessed on 13 October 2020).

32. Baldi, E.; Savastano, S. Fear of Contagion: One of the Most Devious Enemies to Fight During the COVID-19 Pandemic. Disaster Med. Public Health Prep. 2020, 2020, 1-2. [CrossRef]

33. Temesgen, Z.M.; DeSimone, D.C.; Mahmood, M.; Libertin, C.R.; Palraj, B.R.V.; Berbari, E.F. Health Care After the COVID-19 Pandemic and the Influence of Telemedicine. Mayo Clin. Proc. 2020, 95, S66-S68. [CrossRef]

34. Omboni, S. Telemedicine During the COVID-19 in Italy: A Missed Opportunity? Telemed. e-Health 2020, 26, 973-975. [CrossRef] [PubMed] 